\title{
Study of roadside weed diversity along the constructed and non constructed roads in Palghar, Maharashtra, India.
}

Nitesh Joshi $^{*}$, Prachiti Mule ${ }^{1}$, Ambika Joshi ${ }^{2}$

${ }^{1}$ Department of Botany, Rizvi College of Arts, Science and Commerce, Bandra (W), Mumbai, Maharashtra, India

${ }^{2}$ Department of Botany, Jai Hind College, 'A' Road, Churchgate, Mumbai, Maharashtra, India.

Received: June 19, 2016; Accepted: June 27, 2016.

\begin{abstract}
The study aims to explore the floristic diversity of the weeds occurring along the roadside of the Palghar Tehsil by calculating various diversity indices of two distinctly identified sites, one being disturbed, constructed sites with high usage while other is relatively less disturbed mainly non-constructed sites and limited usage. The further purpose of the study was to draw conclusion in terms of floristic differences based on 3 indices viz. Shannon Weiner Index, Species Richness, Species evenness Index, Simpson's Index and Sorenson's Similarity Index. On comparison it was seen that the area that has limited usage has evenly distributed community and rich diversity as compared to another site. Diversity of the community occurring near non constructed road was found to be more as compared to the community occurring near constructed road.
\end{abstract}

Key words: Diversity index; weeds; constructed; non constructed roads; Palghar

\section{Introduction}

Development activities in various areas create direct or indirect impacts on the biodiversity. Although road development provides much needed connectivity; it continues to be a major player in the overall reduction of biodiversity. Habitat fragmentation, loss, corridor restriction directly affects the ecology. Introduction of invasive species through road verges, ecological disequibrilium and transmission of disease can be considered as a negative impact due to the new development. Sometimes roads may also cause a negative impact such as source of barrier for seed dispersion of many species (Angold, 1997). Therefore, to understand the differences in the species distribution; a study and comparison of these developed sites and relatively undeveloped sites is crucial as it possibly will provide the information about the status of biodiversity. Road verges are ecologically and environmentally unique areas that act as habitat for many species. The small marginal habitats in a landscape serve as important passage for movement of a species and support community structure of that area (Sara, 2006). Therefore, study of roadside vegetation has been proposed and accepted throughout the world (Wilson et al., 1992).

\footnotetext{
${ }^{*}$ Corresponding Author:

Dr. Nitesh Joshi,

Associate Professor,

Department of Botany, Rizvi College of Arts,

Science and Commerce, Bandra West,

Mumbai 400050, Maharashtra, India.

E-mail: niteshcjoshi@gmail.com
}

Palghar Tehsil is a rapidly growing semi urban area, situated nearly $70 \mathrm{~km}$ away on the northern side of the Mumbai. The region as well as its surrounding towns is well connected internally with several roads being developed for residential complexes which are fast arising in this town. The proximity of this small town to an major metropolis is resulting in several construction activities, converting barren lands, agricultural plots and areas near ponds or lakes into industrial or residential units.

Ecological assessment of the road verges of constructed and non-constructed roads was done to study changing gradient of distribution and density of weeds along the road. Weeds are plants that are not sown purposely yet are one of important part of the ecosystem in which they are growing.

\section{Materials and Methods}

Study Site: Current study was carried out at 4 different areas viz. Saphale, Palghar, Boisar and Kelwe in the Palghar Tehsil (Figure 1). With an aim to understand the differences in the ground flora two types of sites viz. wellconstructed roads (Primary and secondary) and non-constructed roads were identified in the above mentioned locations and 
quadrants were laid in the month of September.

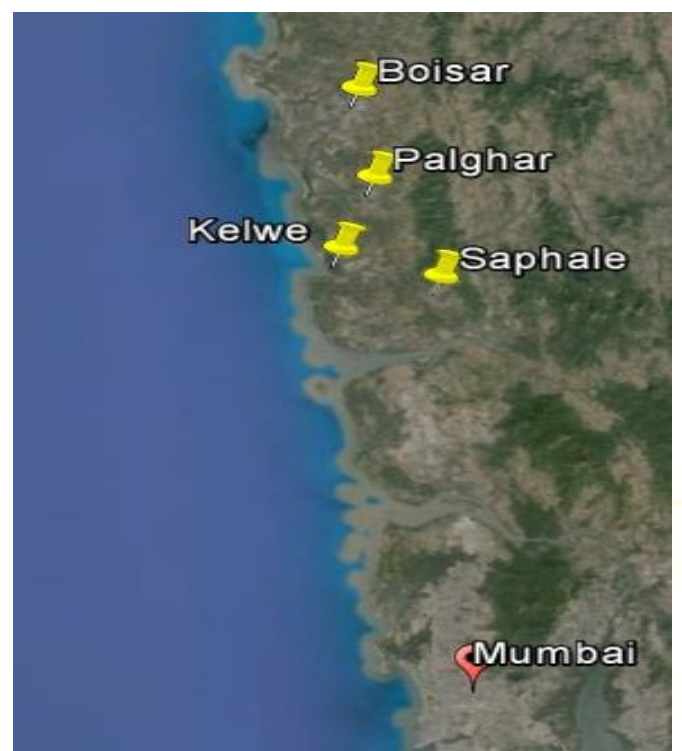

Figure 1: A map showing location of sampling sites

Sampling Methodology: In order to study the differences in the composition of ground flora, random sampling technique was used. A total of 20 list count quadrant of size $1 \mathrm{~m} * 1 \mathrm{~m}$ were plotted at each site to understand weeds diversity.

Data Analysis: Various diversity indices were used to interpret the floral diversity in each quadrant. A single diversity index is insufficient to describe community structure of vegetation over a large range (Beisel et al., 2003), hence four different indices were used to interpret the diversity along the surveyed roads. Species richness index (McIntosh, 1967) was used as it provides a quantitative, comparable measure for diversity of an area. Species evenness index was used because evenness of the vegetation community provides important information about diversity of an area (Hayat and Kudus, 2010). Therefore, species evenness index is considered as one of the important diversity indices. (Bibi and Ali 2013; Hill, 1973; Turchi et al., 1995; Leinster and Cobbold, 2012). Shanon - Weiner index (Shanon and Weaver, 1949) is commonly used to compare diversity between various habitats. (Clarke and Warwick, 2001; Hutchinson, 1970). Simpson's index was used as it provides details about diversity and evenness of a community. Unlike Shanon - Weiner index this index is more sensitive towards evenness than richness. Therefore, it was used to compare the variations. Sorensen's similarity index is a statistical measure used for comparing the similarity of two samples (Sorensen, 1948). Sorenson's measure is regarded as one of the most effective presence/absence similarity measures (Sorensen, 1948; Wolda, 1981). The index is mainly used for identification of species composition in each of the two sites and the species shared between them (Novotny and Weiblen, 2005). The value of the index varies between 0 to 1 . Zero indicates no similarity while 1 indicates maximum similarity. The indices were calculated using following formulae:

\section{Relative frequency:}

Relative frequency $=$ Number of sampling units of occurrence / Total number of units sampled (Soodan and Kumar, 2006)

\section{Relative density:}

Relative density $=$ Number of individuals in a quadrat / Total number of individuals of all the species (Soodan and Kumar, 2006)

\section{Shannon Weiner index:}

Shannon - Wiener index $\left(\mathrm{H}^{\prime}\right)=-\sum \mathrm{Pi} \log _{\mathrm{n}} \mathrm{Pi}$ (Shanon and Weaver, 1949)

Where $\mathrm{Pi}=$ Number of individual of one species / Total Number of all species

\section{Species richness:}

SR $=\log S$ (Krebs, C.J., 2013)

Where $S=$ total number of species

\section{Species evenness index:}

Evenness Index $=\mathrm{H}^{\prime}$ / SR (Heip, Herman and Soetaert, 1998)

Where $\mathrm{H}^{\prime}=$ Shannon - Wiener diversity index; SR $=$ Species Richness

\section{Simpson's Index of Diversity:}

$\lambda=\mathrm{Ni}(\mathrm{Ni}-1) / \mathrm{N}(\mathrm{N}-1)$ (Heip, Herman and Soetaert, 1998)

Where, $\lambda=$ Simpson's diversity index, $\mathrm{Ni}=$ Number of individuals of species; $\mathrm{N}=$ total number of individuals of a community

\section{Sorensen's Similarity Index:}

Sorenson's Similarity index $=2 \mathrm{C} / \mathrm{a}+\mathrm{b}$ (Wolda, 1981) 
Where, $\mathrm{C}=$ number of common species; $\mathrm{a}=$ number of species in community $1 ; b=$ number of species in community 2 .

\section{Results and Discussion \\ Weeds Along Constructed Road:}

A total of 41 different species of weeds belonging to 24 families were found along the constructed road. Members of families Boraginaceae, Cleomaceae, Lytheraceae, Menispermaceae,

Oxalidaceae,

Plantaginaceae and Portulacaceae were seen only along constructed road. To understand most frequent and denser species relative frequency and relative density was calculated. Graphical representation of top ten dominant species along constructed road is shown in figure 2 and figure 3 . It was observed that Impatiens balsamina $\mathrm{L}$. and Celosia argentea $\mathrm{L}$. were most frequent species and showed high density in many quadrants. Impatiens balsamina L. was most frequent species with the relative frequency value as 0.0031 followed by Celosia argentea $\mathrm{L}$. having relative frequency 0.0023. Third most frequent species with the relative frequency value 0.0021 was Blumea lacera (Burn.f.) DC. Four species viz. Alternanthera sessilis (L.) R.Br. ex DC., Cassia tora L., Cyanotis cristata (L.) D. Don. and Vernonia cinerea (L.) Less. showed equivalent relative frequency of 0.0018 . Euphorbia hirta L. exhibited little low relative frequency of 0.0015 as compared to the four species viz. Alternanthera sessilis (L.) R.Br. ex DC., Cassia tora L., Cyanotis cristata (L.) D. Don. and Vernonia cinerea (L.) Less. Achyranthes aspera L. and Aerva lanata (L.) Juss. had lowest relative frequency value of 0.0013 .

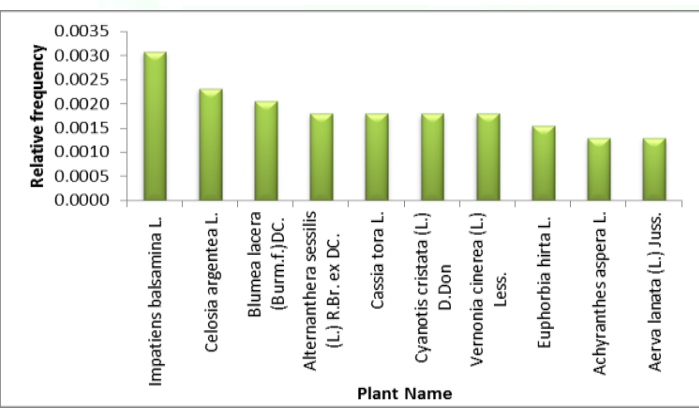

Figure 2: Relative frequency of most dominant weeds along constructed road

Denser species in terms of relative density was Impatiens balsamina L. (relative density 0.116)

followed

by

Celosia argentea L. (relative density 0.077), Phyllanthus niruri L. (relative density 0.064), Achyranthes aspera L. (relative density 0.061), Alternanthera sessilis (L.) R.Br. ex DC. (relative density 0.061), Blumea lacera (Burm.f.) DC. (relative density 0.052), Vernonia cinerea (L.) Less. (relative density 0.049), Cassia tora L. (relative density 0.045) and Tridax procumbens (L.) L. (relative density 0.041). With the value of 0.033 Cyanotis cristata (L.) D. Don showed lowest density.

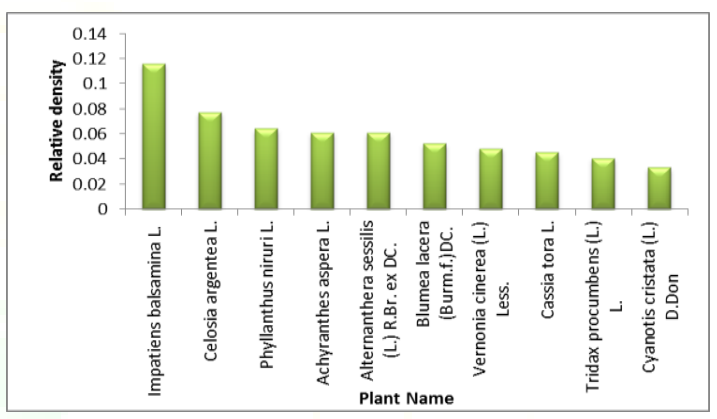

Figure 3: Relative density of most dominant weeds along constructed road

\section{Weeds along non constructed road:}

Along non constructed roads 57 species of weeds belonging to 20 families were seen. Members of family Araceae, Cyperaceae, Malvaceae, Onagraceae, Orobanchaceae, Sapindaceae, Zinziberceae and Colchicaceae were seen only along non constructed road. Figure 4 and figure 5 represents most dominant 10 species along non constructed road. It was seen that Cassia tora L. and Tridax procumbens (L.) L. are the most frequent species with the relative frequency values 0.036 and 0.032 respectively. These were followed by Boerhavia diffusa L. and Celosia argentea L. with the relative frequency value 0.029. 3 species viz. Borreria articularis (L.f.) F. N. Williams, Curcuma pseudomontana J. Graham and Tephrosia purpurea (L.) Pers. exhibited same relative frequency value of 0.025 , while the lowest relative frequency in the dominant ten species was shown by Impatiens balsamina L., Ludwigia perennis $\mathrm{L}$. and Setaria viridis (L.) P. Beauv. In terms of relative density Tridax procumbens (L.) L. was most dense species (relative density 0.077 ) occurring on the field followed by Celosia argentea L. (relative density 0.044), Curcuma pseudomontana J. Graham (relative 
density 0.038), Setaria viridis (L.) P. Beauv. (relative density 0.035), Cassia tora $\mathrm{L}$. (relative density 0.033), Cyperus rotundus L. (relative density 0.030), Senecio bombayensis N. P. Balakr. (relative density 0.030), Desmodium triflorum (L.) DC. (relative density 0.028), Phyllanthus niruri L. (relative density 0.028) and Alternanthera sessilis (L.) R.Br. ex DC. (relative density 0.027).

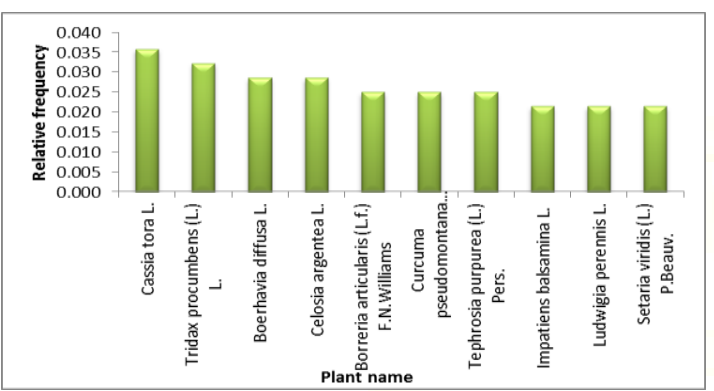

Figure 4: Relative frequency of most dominant weeds along non constructed road

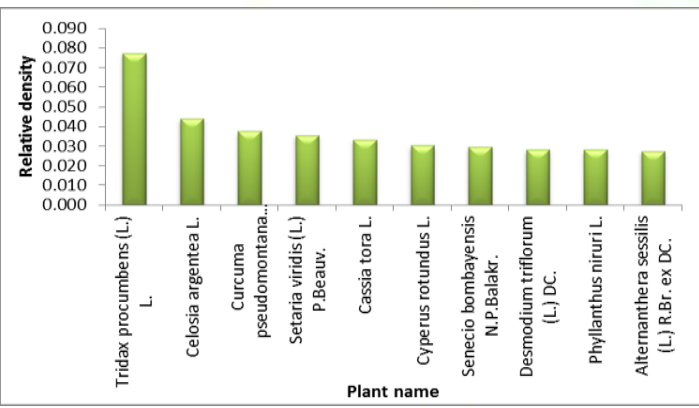

Figure 5: Relative density of most dominant weeds along non constructed road

\section{Variation in diversity:}

Figure 6 and 7 shows the variations in the diversity along the constructed and non constructed road. The Shannon Wiener Index and Simpson's Index clearly showed that at all four locations, diversity at roadside of a non constructed road was more as compared to the constructed road. The trend of species richness at various locations was different. At the Palghar, Boisar and Kelwe location higher values of species richness were recorded at constructed roadside as compared to non constructed road. At Saphale location species richness of non constructed roadside was high as compared to constructed roadside site. The value of Simpson's index varied as the species richness of the community varied at different locations. Species evenness values for various locations in all sampling sites showed slight deviation indicating absence of single species dominance.

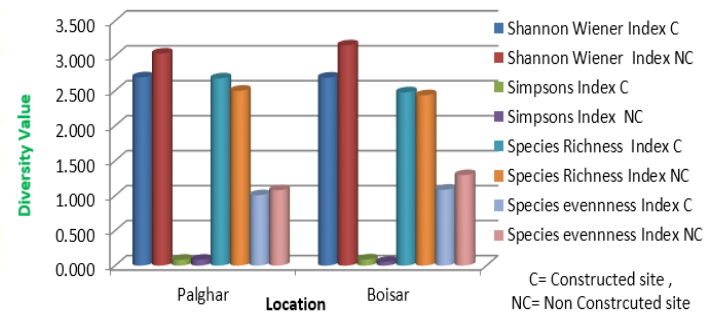

Figure 6: Presentation of calculated diversity values for species recorded at two locations viz. Palghar and Boisar
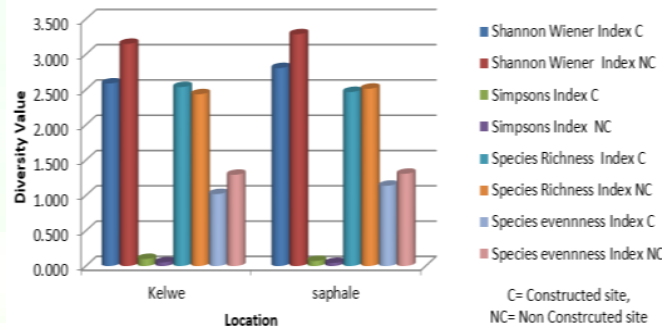

Figure 7: Presentation of calculated diversity values for species recorded at two locations viz. Kelwe and Saphale

Sorensen's similarity index was calculated for the two sites viz. occurring near roadside of a constructed road and occurring near roadside of a non-constructed road. The value was found to be 0.143 indicating minimal similarity between the two communities.

Table 1: Shannon Weiner, Simpson's, Species richness and evenness values recorded at constructed and non constructed sites of Palghar and Boisar

\begin{tabular}{lcccccccc}
\hline \multirow{2}{*}{ Diversity Index } & \multicolumn{2}{c}{ Palghar } & \multicolumn{2}{c}{ Boisar } & \multicolumn{2}{c}{ Kelwe } & \multicolumn{2}{c}{ Saphale } \\
\cline { 2 - 9 } & $\mathbf{C}$ & NC & C & NC & C & NC & C & NC \\
\hline Shannon Wiener Index & 2.692 & 3.031 & 2.688 & 3.149 & 2.588 & 3.149 & 2.806 & 3.285 \\
Simpsons Index & 0.082 & 0.082 & 0.087 & 0.053 & 0.100 & 0.053 & 0.072 & 0.044 \\
Species Richness Index & 2.677 & 2.500 & 2.477 & 2.435 & 2.537 & 2.435 & 2.467 & 2.513 \\
Species evenness Index & 1.006 & 1.077 & 1.085 & 1.293 & 1.020 & 1.293 & 1.137 & 1.307 \\
\hline
\end{tabular}




\section{Conclusion}

Two types of weed community viz. occurring near roadside of a constructed road and occurring near roadside of a nonconstructed road were selected for the current study with the aim to know the differences in their composition. The study revealed the fact that the composition of the ground flora is very much different at different sites. There were certain plants occurring in both communities but community structure of the population varied significantly. Although species richness of constructed roadside community was found more at 3 different locations; when considered in terms of evenness and types of species occurring at a particular site, it was found that diversity of the community occurring near non constructed road was found to be more as compared to the community occurring near constructed road. Palghar is a forthcoming suburb of Mumbai and is developing at a faster rate. Modifications in the landscape due to infrastructural changes may hamper the species richness in this area. This work is a data base that can be used in future for conserving the biodiversity and in achieving the sustainable development.

\section{Acknowledgement}

Authors are thankful to Dr. Farooqui, Principal, Rizvi College, Bandra for his unrelenting support and Mr. Siddesh Gajare for assistance on field.

\section{References}

1. Angold PG, The impact of a road upon adjacent heathland vegetation: effects on plant species composition Journal of Applied Ecology, 1997, 34, 409-417.

2. Beisel JN, Usseglio-Polatera P, Bachmann V, Moreteau JC, A comparative analysis of evenness index sensitivity, International Review of Hydrobiology, 2003, 88, 3-15.

3. Bibi F, Ali Z, Measurement of Diversity Indices of Avian Communities at Taunsa Barrage Wildlife Sanctuary Pakistan, The Journal of Animal \& Plant Sciences, 2013, 23(2), 469-474.
4. Clarke KR, Warwick RM, Change in Marine Communities: an approach to statistical analysis and interpretation second edition, Plymouth Marine Laboratory, UK, Primer E Ltd., 2001.

5. Hayat MSA, Kudus KA, Assessment of Plant Species Diversity at Pasir Tengkorak Forest Reserve, Langkawi Island, Malaysia, Journal of Agricultural Science, 2010, 2(1), 31-38.

6. Heip CR, Peter MJ, Herman, Soetaert K, Indices of Evenness: Netherlands Institute of Ecology. 1998 Center for Estuarine and Coastal Ecology. Vol. II.

7. Hill MO, Diversity and Evenness: A Unifying Notation and Its Consequences, Ecology, 1973, 54(2), 427 432.

8. Hutchinson GE, The Chemical Ecology of Three Species of Myriophyllum (Angiospermae, Haloragaceae), 1970, Limnology and Oceanography 15(1), 15 .

9. Krebs CJ, Ecological Methodology, 3rd Edition, 2013, Chicago: The University of Chicago Press.

10. Kumar R, Soodan AS, A biodiversity approach to check Parthenium hysterophorus L, 2006, Journal of Environmental Biology, 27(2), 349-353.

11. Leinster T, Cobbold CA, Measuring diversity: the importance of species similarity, Ecology, 93(3), 477-489.

12. McIntosh RP, An index of diversity and the relation of certain concepts to diversity, Ecology, 1967, 48, 392-404.

13. Sara A, Plant species richness in midfield islets and road verges-The effect of landscape fragmentation Biological Conservation, 127(40), 500509.

14. Shannon CE, Weaver W, The Mathematical Theory of Communication, 1949, Urbana, IL: University of Illinois Press. 
15. Sorensen TA, A method of establishing groups of equal amplitude in plant sociology based on similarity of species content, and its application to analyses of the vegetation on Danish commons, 1948, K dan Vidensk Selsk Biol Skr 5, 134.

16. Turchi GM, Kennedy PL, Urban D, Hein $\mathrm{D}$, Bird species richness in relation to isolation of aspen habitats,1995, Wilson Bulletin, 107, 463-474.

17. Wilson et al., Road verge management for wildlife, Plant communities, New Zealand.
18. Wolda H, Seasonality of leafhoppers (Homoptera) on Barro Colorado Island. In: EG Leigh, AS Rand, DM Windsor (eds), Ecology of a tropical forest: Seasonal rhythms and longterm changes, 1981, Smithsonian Press, Washington (in press).

\section{Cite this article as:}

Nitesh Joshi, Prachiti Mule, Ambika Joshi. Study of roadside weed diversity along the constructed and non constructed roads in Palghar, Maharashtra, India. Annals of Plant Sciences 5.6 (2016): 1363-1367.

DOI:http://dx.doi.org/10.21746/aps.2016.06.004 